\title{
Enhancement of Information Design and its Retrieval in Glucose Monitoring Device
}

\section{Chatterjee $S^{*}$}

Assistant Professor, Indian Information of Information Technology, Design and Manufacturing, India

*Corresponding author: Dr. Chatterjee Shekhar, Indian Information of Information

\section{Review article}

Volume 3 Issue 1

Received Date: December 05, 2018

Published Date: January 09, 2019

DOI: $10.23880 /$ eoij-16000190

Technology, Design and Manufacturing, Jabalpur, India, Tel: 9425150936; Email: schatterjee1971@gamil.com

\section{Abstract}

Today we are living in emerging world where doctors, engineers and designers are collaborating for growth and development of Health care sector. Researchers are not only working on the cure and treatment of severe diseases but also taking care of their monitoring aspect. In current scenario, we are battling against diseases with no cure such as Cancer, Alzheimer's, HIV and diabetes. Diabetes is spanning day by day in every generation around the world because of our unhealthy life style and ignorance towards precautions. According to IDF, the numbers of diabetics in the world are 365 million, representing around $8.5 \%$ of the global population. India has the highest number of diabetics in the entire world. In diabetes, glucose monitoring is crucial as it can be lethal if not checked regularly. Even with the discovery of glucose monitoring system days back in 1960s, its technology is still fresh and foreign to our population. Most of the glucose monitoring devices available in India is developed by foreign companies. User manual, patient leaflet and device interface is inspired by taking into account of emotions, life style and knowledge of foreign population. Glucose meter, which comes with measuring strips, is widely available in India and measuring glucose level with it, is a com plex task. To make this measuring task simple for the user and offer better information regardless of age, gender and education is the demand of Indian users. Therefore, Designing and developing it for Indian population is a necessity. It should be designed in such a way that Indian users can connect with and understand it with their present knowledge.

Keywords: Monitoring Device; Designs

\section{Introduction}

In this study, several methodologies were followed to understand the problem faced by Indian users while handling new device and test was conducted to know the readability ease of patient leaflet. First, an online survey was conducted to analyze the patient population. Contextual enquiry was carried out by interviewing patients and doctors. Questionnaire survey and task analysis was conducted by observing participants and their activities. Instructional analysis was performed using Gunning fog index and Flesch Reading Ease score. 


\section{Ergonomics International Journal}

From the survey, it was analysed that major population suffering from the disease lies in age groups 25 years onwards. In general, patients do not like to handle monitoring system by their own and requires assistance to perform the task. During discussion, Doctors suggested that ACCU-CHEK glucometer is most reliable, easily available and cheap (in terms of test strip). Task analysis was done on graduate and post graduate students, who never operated the device before, which resulted in interpreting errors made by new users. Readability test shows that instruction in manual lies in 6 or 7 grade level. As a result of this study, a patient leaflet was designed with appropriate task flow with minimal use of scientific language. Legibility and readability of leaflet was improved for elderly and visually impaired users. Work on interface of the device was also done to improve its interaction with the user. Further huge scope of work is identified in this field in India, in terms of guideline formation for patient leaflet, development of readability test, designing form and aesthetics of device, designing low cost meters and designing for blinds.

\section{Background}

Today we are living in emerging world where doctors, engineers and designers are collaborating for growth and development of Health care sector. Researchers are not only working on the cure and treatment of severe diseases but also taking care of their monitoring aspect. In current scenario, we are battling against diseases with no cure such as Cancer, Alzheimer's, HIV and diabetes. Diabetes is spanning day by day in every generation around the world because of our unhealthy life style and ignorance towards precautions. According to IDF, the numbers of diabetics in the world are 365 million, representing around $8.5 \%$ of the global population. India has the highest number of diabetics in the entire world. In diabetes, glucose monitoring is crucial as it can be lethal if not checked regularly [1].

\section{Motivation}

Now a day, health care sector is focusing towards prevention and monitoring of disease. Multiple monitoring equipment and products are getting launched to help the patient to monitor particular disease. On global level companies are investing and carrying out research to make such device efficient for users. If we only talk about the disease like diabetes which has no cure, then its monitoring is the major part while treatment of the disease. There were around 69.1 million incidents of diabetes in India in 2015, hence India has a huge market and opportunity to contribute in this sector. When it comes to the disease like diabetes, its association with other diseases like heart problems, blood pressure, and obesity also make it one of the deadly disease. These diseases come in list of second major diseased which are perishing globally. Today Prevalence of diabetes in adults is 8.7. This motivates engineers and designers to take disease like diabetes towards the best possible cure $[2,3]$.

\section{Problem Definition}

While analysing different features of treatment of diabetes, its monitoring system and cure was recognised as one of the area that demands the attention of designers and engineers. Further, a necessity of redesigning patient leaflet for diabetes monitoring system i.e. Accu-chek is identified for elderly patients in India, which was further established on the feedback of the doctors, as monitoring this disease is the major part in its treatment. The intensive user research was performed to recognise the requirement of users. Some serious key understandings developed after analysing the Data. While redesigning leaflet, all users were studied i.e. young and elderly patients, Doctors, Nurses, etc. Following are the crucial issues which were considered when redesigning the leaflet and interface of device:

- Error less monitoring of diabetes

- Device interface and leaflet design considering visual impartment in elderly's[s]

- Teaching and making user aware of all the tasks

- Reducing biohazard by inducing proper disposal methods

\section{Need Statement}

These days, scientists are working to make glucose monitoring devices better both in terms of functionality and aesthetics in terms of device form. Measuring glucose level is itself a complex task if we talk about glucose meter which comes with measuring strips which is the type of glucose meter widely available in India.

- To make this measuring task less complex for the user

- Providing better information regardless the age, gender and education.

\section{Research Gap}

Factors affecting inefficient use of glucose metre

$>\quad$ Physical Attributes

- Folding crease coming in between text and hindering its readability

- Scientific words are used to convey the massage

- Progress of task was not defined properly

- Guidance to the next step is somewhat confusing 


\section{Ergonomics International Journal}

- Proper overview of product was missing

\section{$>\quad$ Cognitive attributes}

- Mental model of users

- Hierarchy of information

- Overloading of text

- Data chunking

- Lack of readability

- Lack of legibility

- Understand ability of icons and messages

\section{$>\quad$ Mental model of Indian users}

- English is secondary language for Indian population. Existing Leaflet was designed according to education and knowledge of foreign population. Focus should be put to design it for Indian population.

- Diabetic patients now a day lies in every age. It is easy for younger population to understand the device easily due to exposure with technology while elderly patient found it difficult to understand the complex task.

- Fear of pricking of fingers

- Feels need of assistance when patient is visually impaired

- Pre- determined notions make it hard for the individual to change his view.

\section{Objective}

Most of the glucose monitoring devices available in India are developed by foreign companies. User manual, patient leaflet and device interface is inspired by taking into account of emotions, life style and knowledge of foreign population.

To develop information system and ergonomic improvement for handling monitoring device properly and take reading with least errors and to make this measuring task simple for the user and offer better information regardless of age, gender and education, is the demand of Indian users. Therefore, Designing and developing it for Indian population is a necessity. It should be designed in such a way that Indian users can connect with and understand it with their present knowledge.

\section{Home Use Device}

A home use medical device, is a medical device premeditated for users in any environment outside of a professional healthcare facility. This includes devices intended for use in both professional healthcare facilities and homes. Its user is a patient or care recipient, caregiver, or family member/friends who directly uses the device or delivers assistance in using the device.

\section{Glucose meter}

A glucometer, also known as a glucose meter or blood glucose monitoring device, is a home measurement system, which you can use to test the amount of glucose present in your blood.

\section{Home Blood Sugar Testing}

It is recommended for every diabetic patient to keep in check their diabetes regularly. Checking it can help the patient to keep the disease in order, as required. Regular testing can also help the individual avoid catching longterm health related issues that might occur due to diabetic condition.

About 40 million diabetics are currently present, amongst them only half a million checks their blood glucose level on regular basis, as industry suggests. According to some studies diabetes prone deaths can be reduced down by $52 \%$ if the glucose level in the body gets regularly checked up and controlled, says Sanjay Gupta, head of diabetes care, India and neighbouring markets of Roche Diagnostics.

\section{Way to Test Your Blood Sugar}

Traditional Home Glucose Monitoring: The usual way to check blood sugar levels is by:

- Pricking the fingertip with a lancing device

- Putting the blood drop on a test strip

- Putting the test strip into a glucose meter

- Reading the blood glucose level displayed on the meter

\section{Working Principle of Glucose meter}

Glucometer sensor (test strips): Glucose meter works on the principle of electro enzymatic sensor, in which glucose oxidation occurs with the help of glucose oxidase enzyme. Glucose oxidase performs a chemical reaction of glucose and oxygen, which in turn leads to increase in $\mathrm{pH}$ and decrease in partial pressure of oxygen. In this chemical reaction glucose turns into glycolic acid.

Usually the glucose strips used to determine the concentration of glucose in blood has three terminal electrodes present in it. Which are as follows:

- Reference electrode

- Working electrode

- Trigger electrode 


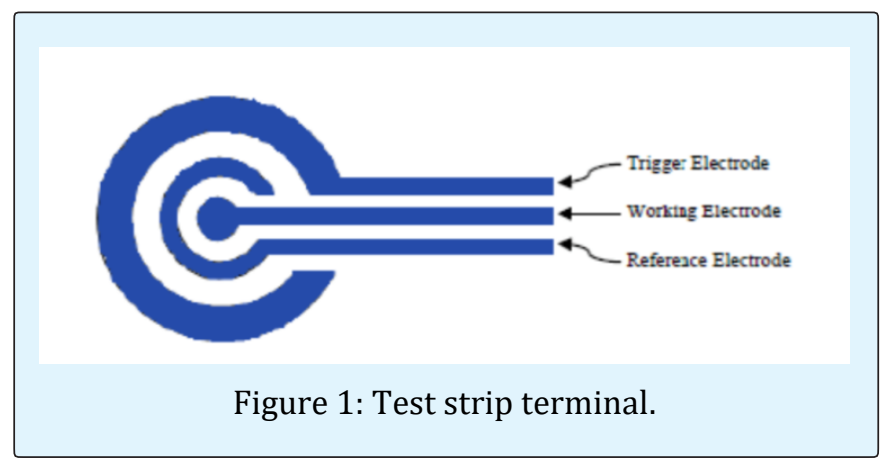

Negative voltage of -4 volts gets developed when blood comes in contact with the strip, it allows the conversion of chemical reaction into electrical signals. These signals get displayed on the device screen as these signals are equivalent to the amount of glucose in blood.

\section{Advantage of Glucose meter}

When we talk about the advantage related to testing the blood regularly with glucose meter some of the major effects comes into the mind like:

- It helps taking care of diabetics and take control over it.

- It helps patient doctor to decide right medication for them.

- It also helps patient to keep track on their diet, stress, health and other diabetic related complications.

Diabetes monitoring can only regulate the insulin dependent patients to calculate their dose before taking it.

\begin{tabular}{|c|c|}
\hline $\begin{array}{c}\text { Typical self- } \\
\text { monitoring regimen }\end{array}$ & Recommendations \\
\hline A & $\begin{array}{c}\text { Periodic testing to meet needs at } \\
\text { a time }\end{array}$ \\
\hline B & $\begin{array}{c}1-2 \text { tests daily, varying times of } \\
\text { testing }\end{array}$ \\
\hline C & 4 test per day * 2 days a week \\
\hline D & 4 test per day each day \\
\hline E & $\begin{array}{c}\text { test per day pre and postmeals } \\
\text { and before bed }\end{array}$ \\
\hline
\end{tabular}

Table 1: Diabetes monitoring schedule.

\section{Advancement in Glucose monitoring}

- Implantable sensors are now a day, a major research area for monitoring diabetes and are under clinical testing. These sensors have tiny needles implanted under the skin. These needle tips carry chemicals and reacts with glucose present in the tissue to create an electrical signal. Rest of the process is similar to the mechanism of most glucometers. The electrical signal can then be transferred to a wristwatch-size receiver that can decode the signal as a glucose value which is readable on receiver screen.

- In another system a tiny laser beam is used to form a microscope puncture in the skin through which small drops of tissue fluid is obtained. The device can then measure the glucose in the fluid in a manner similar to the earlier defined device. The researchers of this device tried to combine it in the same small size receiver. This device is still several years away from general use.

- Researchers are also focussing on building bloodless meters, these meters would not require pricking the finger to measure blood glucose level. At Kansas State University, a similar technology was created for the food industry using a laser beam to determine the sugar content of fruit without rupturing their skin. Unfortunately, this technology is more complex for use in humans, as skin thickness varies across individuals, and temperature lead to varies the accuracy.

- Implantable glucose biosensors are also a huge project which allows monitoring blood glucose and eliminating the need for finger pricks. The biosensor uses an enzyme specific for glucose. Once implanted in subcutaneous tissue, the biosensor will provide continuous, accurate checking of blood glucose.

\section{Problem Identification}

There were several problems identified in glucometer as a product:

\section{Device and its Components}

- Ergonomic aspect of device was not proper.

- Not designed according to Indian anthropometry

- Device and screen both are dark in color, difficult to distinguish.

- No back lit to read device in din light or at night

- Marking on the device (lancing) is confusing

- Hard to open the battery area of device.

- Lancets are very small in size to hold properly.

- Cap of the strip container id too tight and uneasy to open

\section{Leaflet}

- Least priority was given to product over view.

- Fonts are small and not properly visible

- Blue Colored fonts for additional instructions are confusing and not legible.

- No feedback while moving forward in task. 
- Folding creases are coming over text making it difficult to read

- Paper of leaflet was glossy.

- Information related to customer care is not at all visible.

- Reference for the next guide is missing.

- Color of the leaflet is is inappropriate for elderly and colorblind users

- Too much use of scientific language.

\section{Interface}

- Interface was complex for new users

- Finding averages and setting date \& time was complex

- Some messages were not clear and understandable

- Averages denoted as "ave" in a very small font

- No space left on screen for shadow of device

- Icons were not visible and logical

\section{Existing Design}

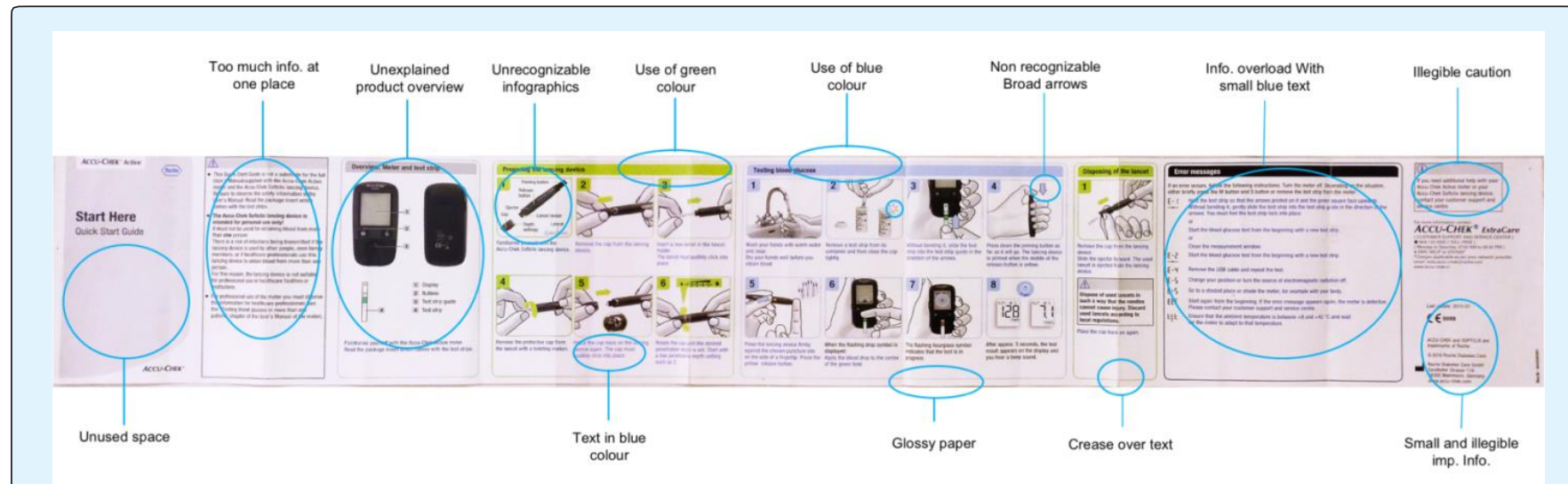

Figure 2: Existing leaflet design with some marked problems.

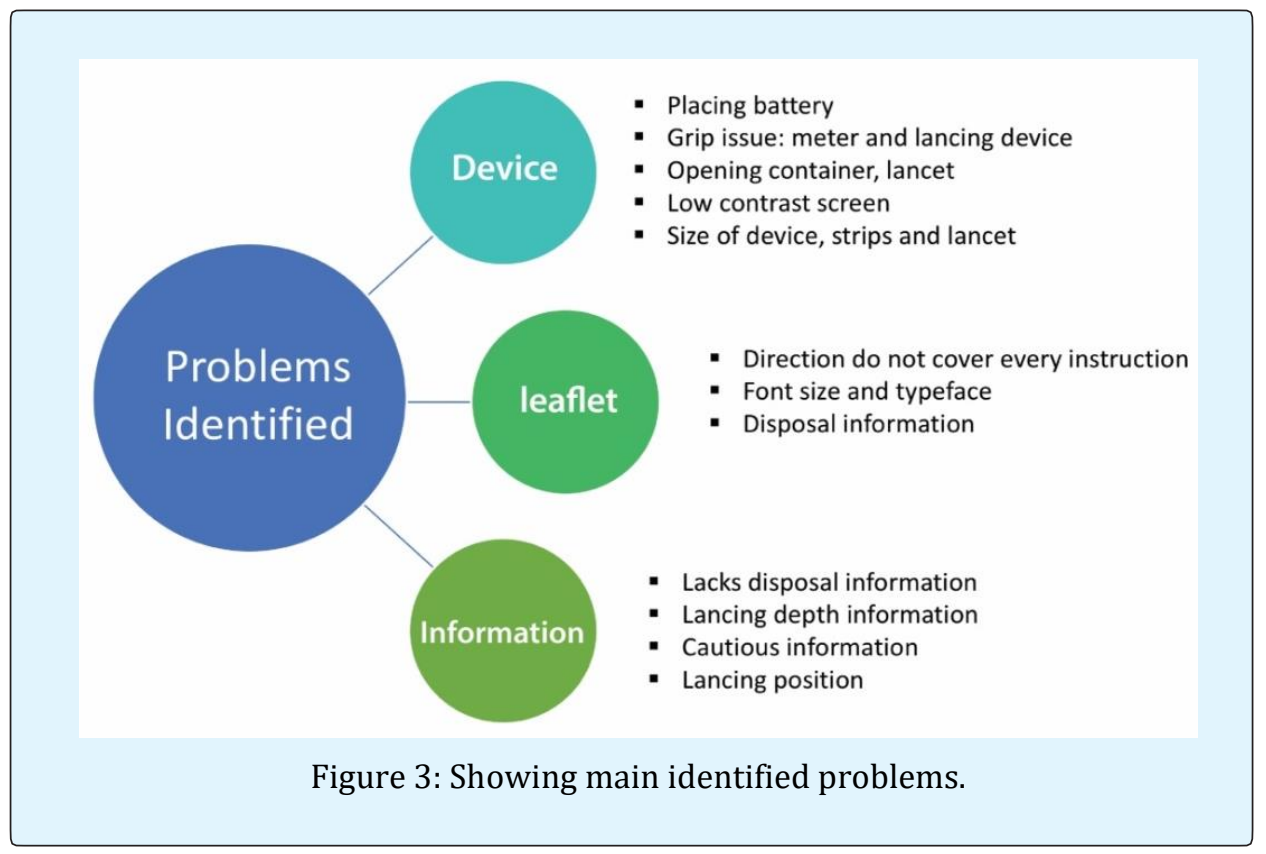




\section{Target users identified were:}

- Users having any kind of eyesight related issue like glaucoma, colorblindness, cataract, and shortsightedness.

- Elderly people living alone and don't have anyone nearby them to assist while performing the task.

- Users lacking higher education who are not very much familiar with the scientific language.

- Teenagers with diabetes issue.

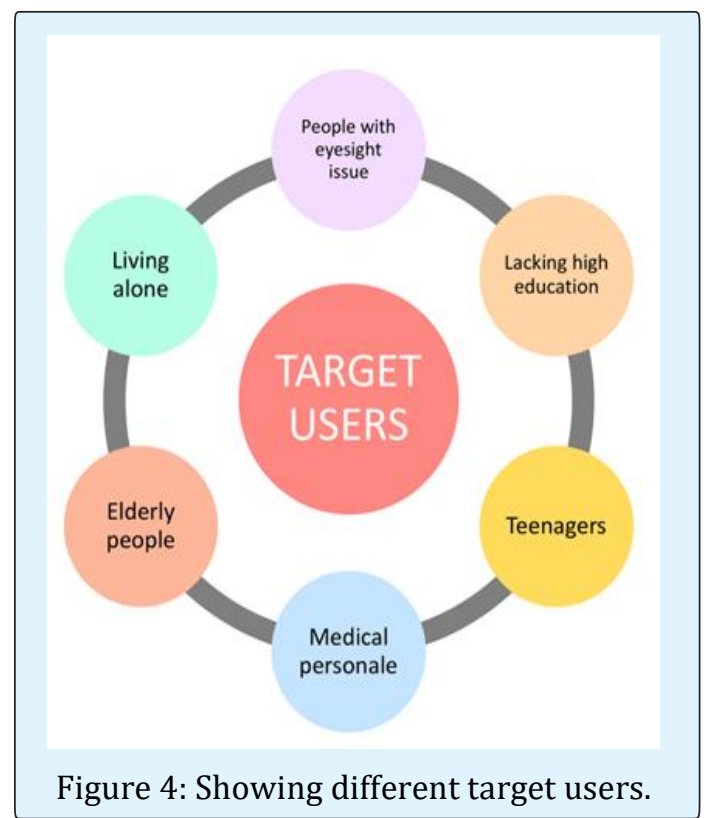

\section{Concept Generation (Leaflet)}

This phase of thesis mainly focuses on, generating set of design concepts to cater the identified needs. Main motive of concept generation is to creatively ideate solutions which are feasible. While ideation process, the primary focus was to improve the readability and legibility of the leaflet for every age group. Along with the primary focus, secondary focus was to prevent make users learn all the steps thoroughly and to get proper feedback while performing all the steps.

\section{Hierarchy of Information}

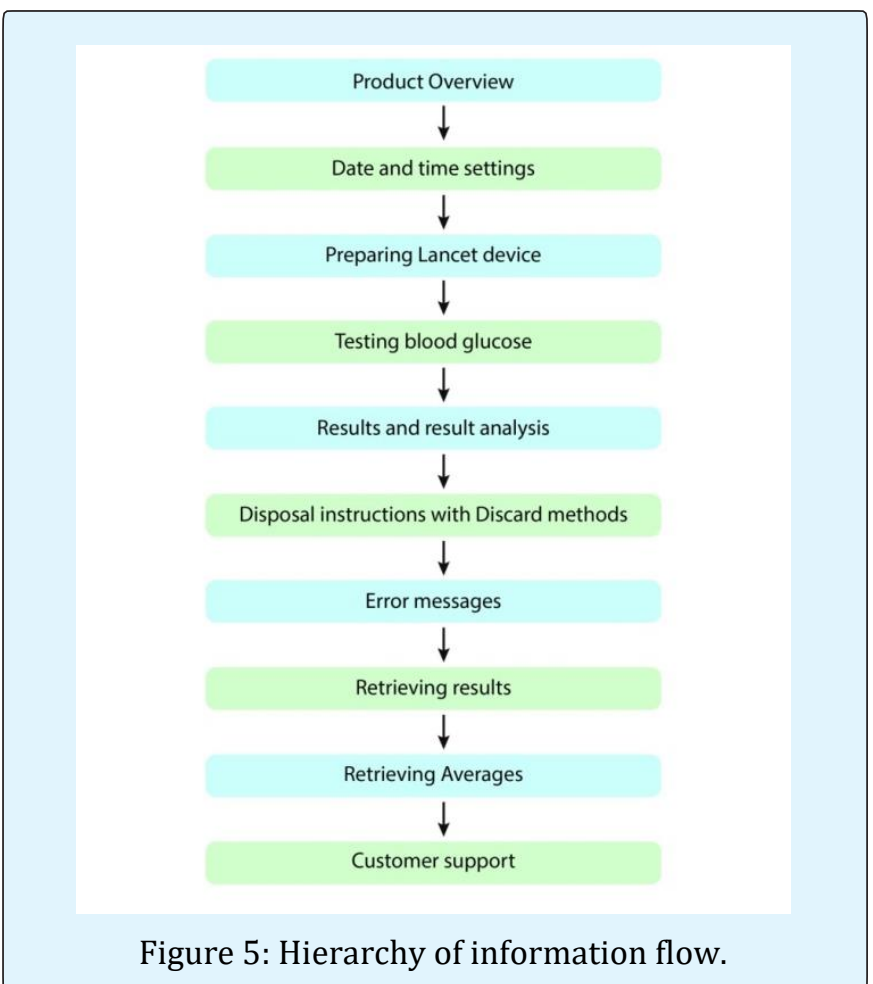

\section{Concept Generation (Interface)}

This concept is based on redesigning of simple interface for glucose meter. The $0.2 \mathrm{~cm}$ margins were given to avoid shadow falls on the display. Readability and easily recognition are the two main factors which were kept in mind while designing. As it is based on hardware parts used to define the display objects less number of objects were moved to maintain the hardware cost.

\section{$>\quad$ Concept One}

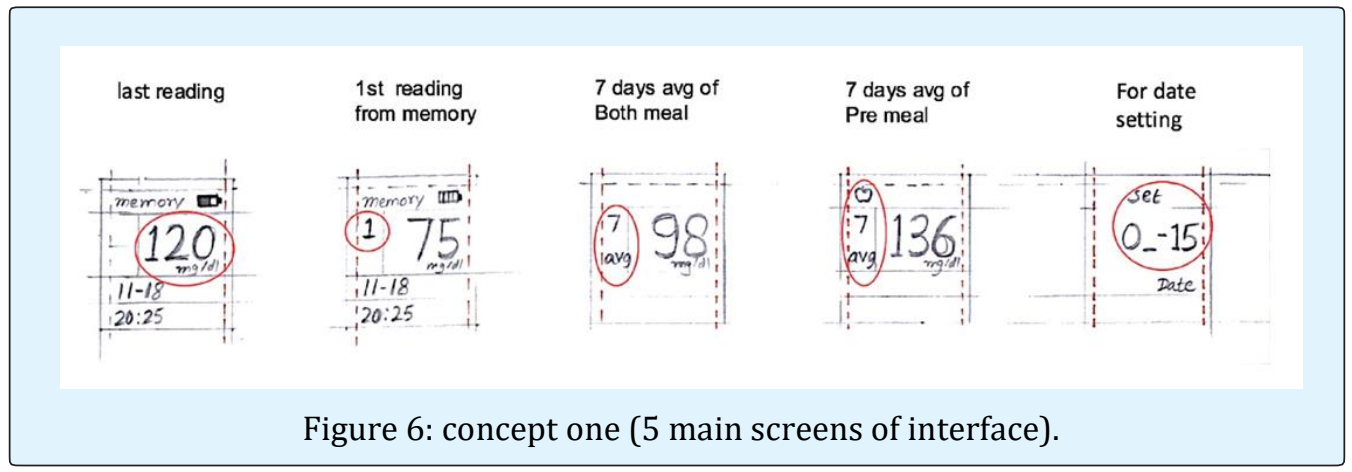




\section{Ergonomics International Journal}

\section{Strength of concept is as follows:}

- Quadrants were divided in straight pattern both vertically and horizontally.

- No movement in icon positions and Letter position leading to the very less changes in device hardware.

- Battery indicator was given at the top along with the headings which suits mental model of users.
- Date and time values were indicated with their names on their side.

- Optimum size and space given to display readings.

Limitations of concept are as follows:

- Change of icons with message

- Limited space for reading display

\section{$>\quad$ Concept two}

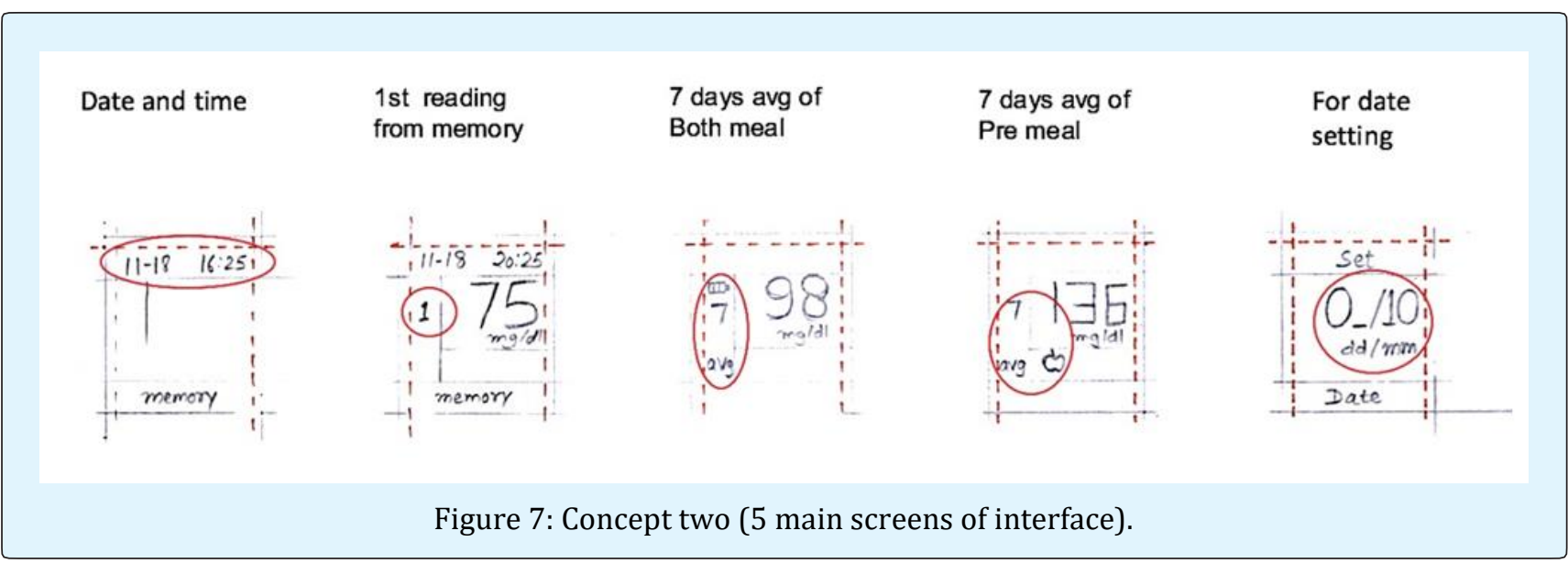

Strength of concept is as follows:

- Quadrants were divided in straight and L-shaped pattern.

- Almost no movement in icon positions and Letter position.

- Straight pattern was defined to show icons and reading related information.

- Units displayed in simpler way while settings.

- Headings were defined on down side of screen.

- Optimum size and space given to display readings.

- Date and time was displayed on the top to get the first clear view.

\section{Limitation of concept is as follows:}

- Battery indicator was given in side which might not align with user mental model.

- Date and time values were not indicated with their names.

- Heading in downside can be missed by users, as mental model always recognises headings on the top.

\section{$>\quad$ Concept three}

Fig 35: Concept three (5 main screens of interface)
Strength of concept is as follows:

- Quadrants were divided in straight pattern.

- Almost no movement in icon positions and Letter position.

- Units displayed in simpler way.

- Headings were defined on down side of screen.

- Bigger size and space given to display readings.

Limitations of concept are as follows:

- Date and time values were not indicated with their names.

- Heading in downside with battery indicator can be missed by users, as mental model always recognises headings on the top.

\section{Final Concept}

\section{Concept Generation (Booklet)}

A daily diary for keeping written record of user diabetes was designed, as elderly people don't want to play with technology. Diary is for those users who likes to maintain their diabetes record by themselves and to show and take proper consultation with their doctor by showing their record in every visit. 


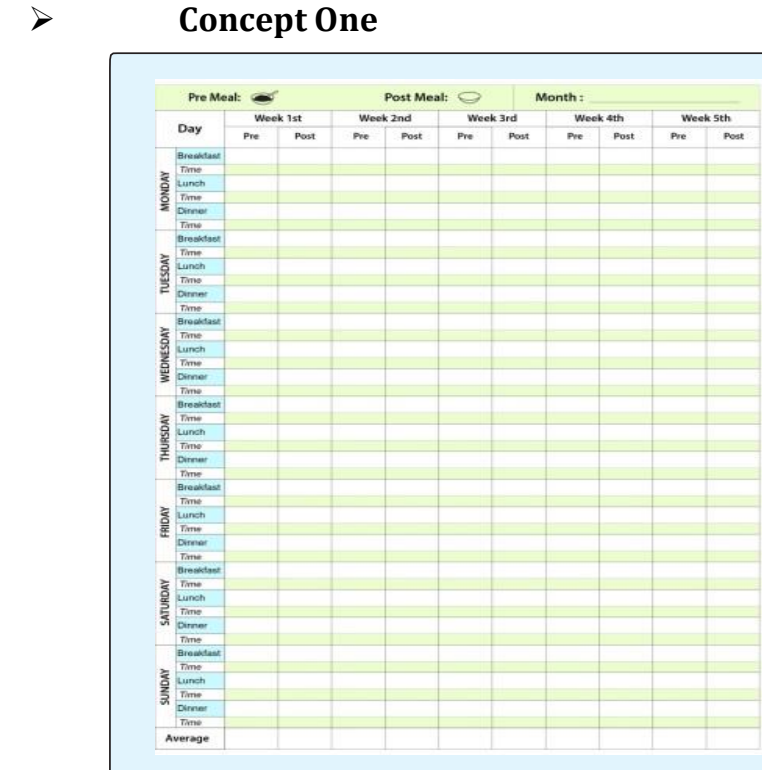

Strength of concept is as follows:

- Allows left to right writing pattern.

- Whole month will be reviewed in one page.

- Area was provided to get the average of every kind of meal (like Avg of Pre breakfast, Avg of Post breakfast and so on) taken in whole month.

- Time slot is there for both pre and post meals.

\section{Limitations of concept are as follows:}

- Booklet size is A4.

- Comments area was not provided.

- Little bit big in size to carry.

Figure 8: Concept one (Daily record book).

\section{Concept two}

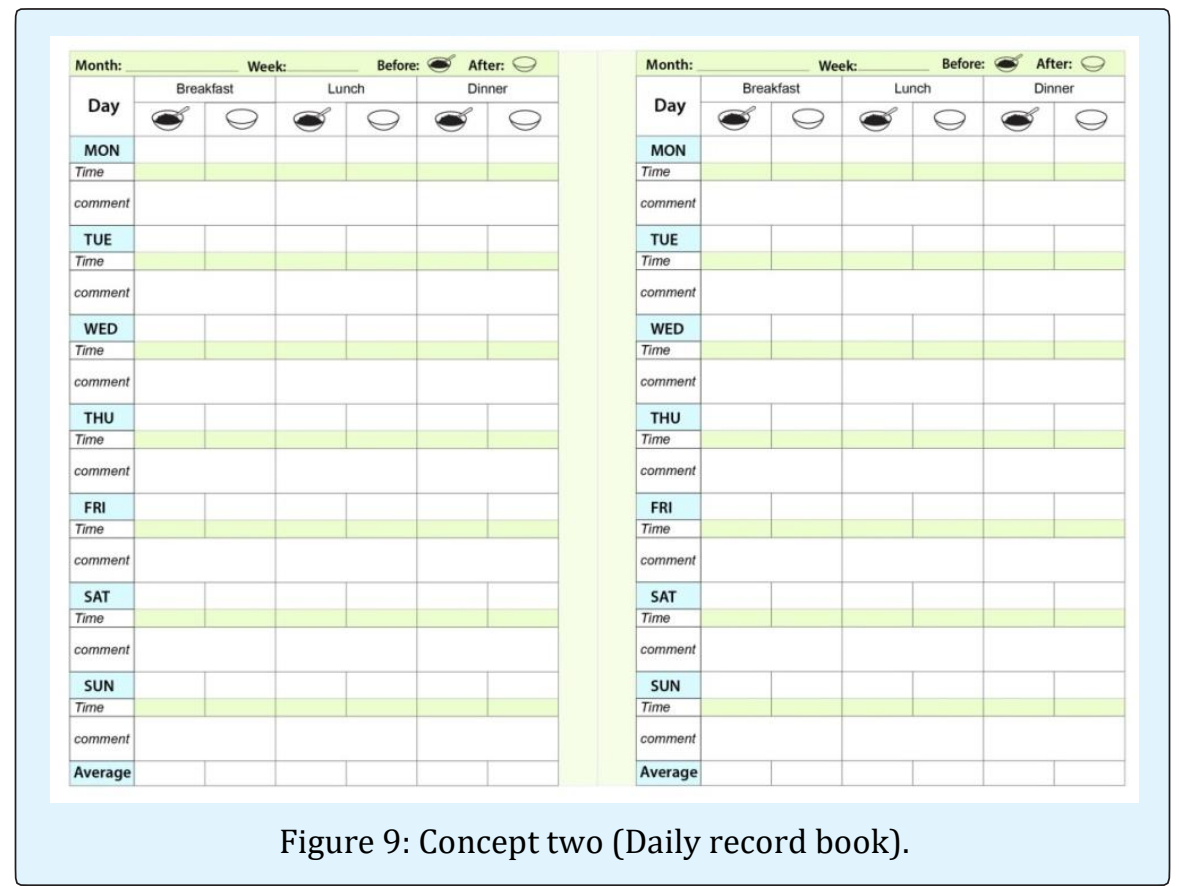

Strength of concept is as follows:

- Allows left to right writing pattern.

- Whole week of one month will be reviewed in one page.

- Area is provided to get the average of every kind of meal (like Avg of Pre breakfast, Avg of Post breakfast and so on) taken in whole month.

- Time slot is there for both pre and post meals.

- Enough area for comment/remark is provided.

- Size of booklet is small i.e. A5, and is easy to carry.

- Date section is provided. 


\section{Ergonomics International Journal}

Limitation of concept is as follows:

- Requires multiple pages to cover whole month

\section{Final Design}

Concept two is considered as the final design, as it is easy to carry, having comment and date section to write.

(A)Inner page

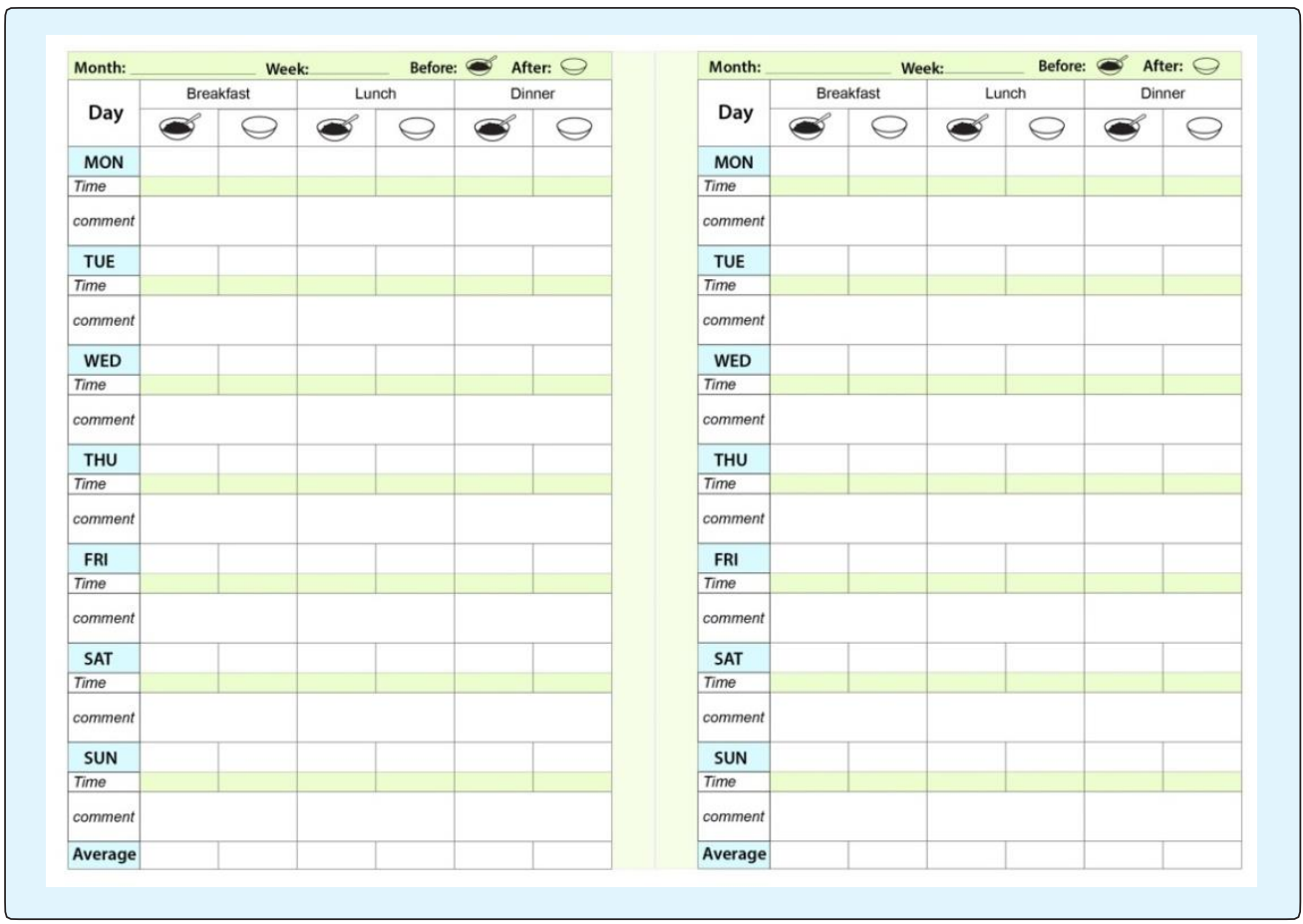

(B)Outer Page

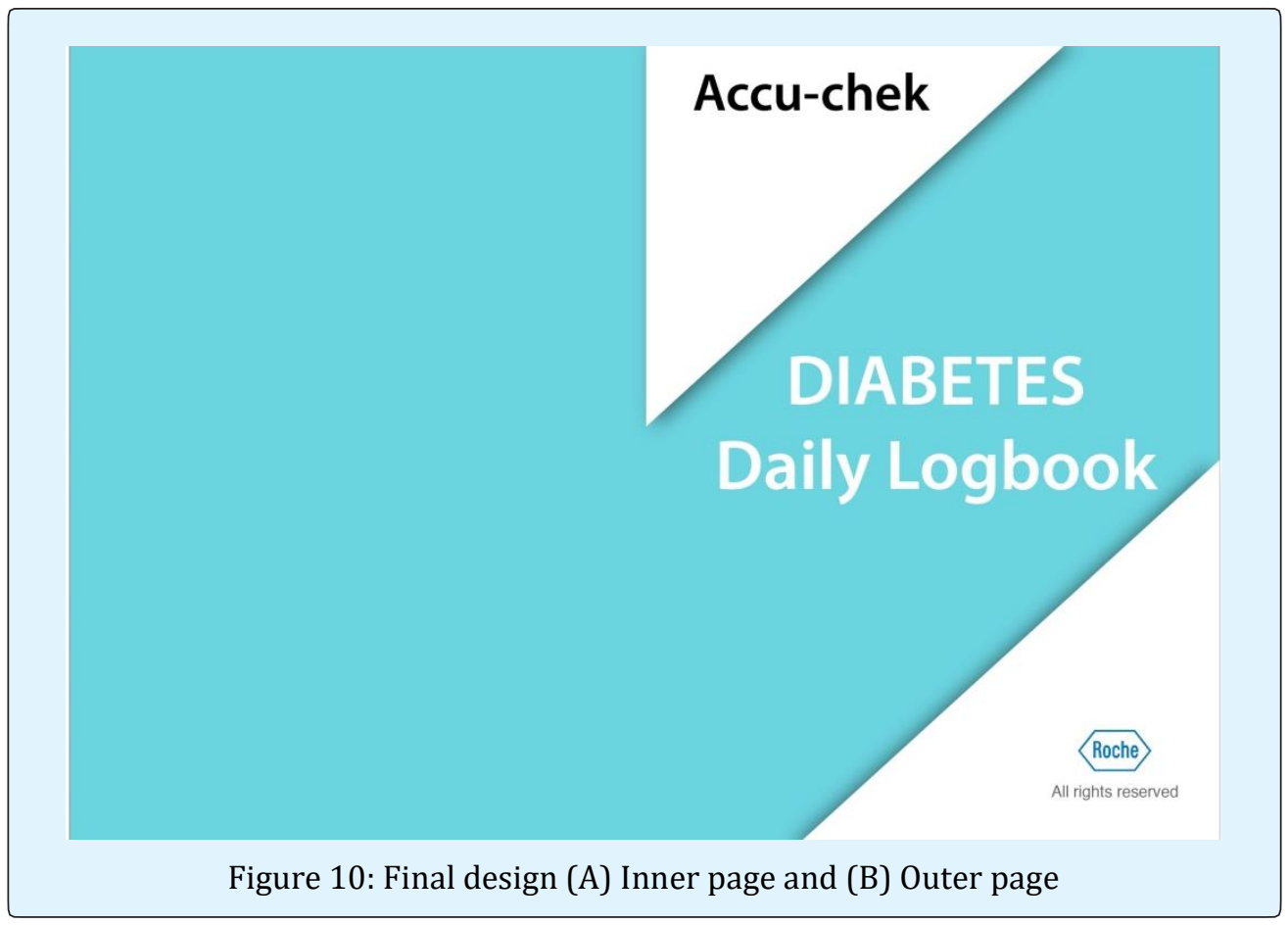




\section{Hand Illustrations}

Hand illustrations have been made to guide while doing the task. Illustrations are kept clean and simple to guide the users while performing task. Designed taking double visual check in consideration.

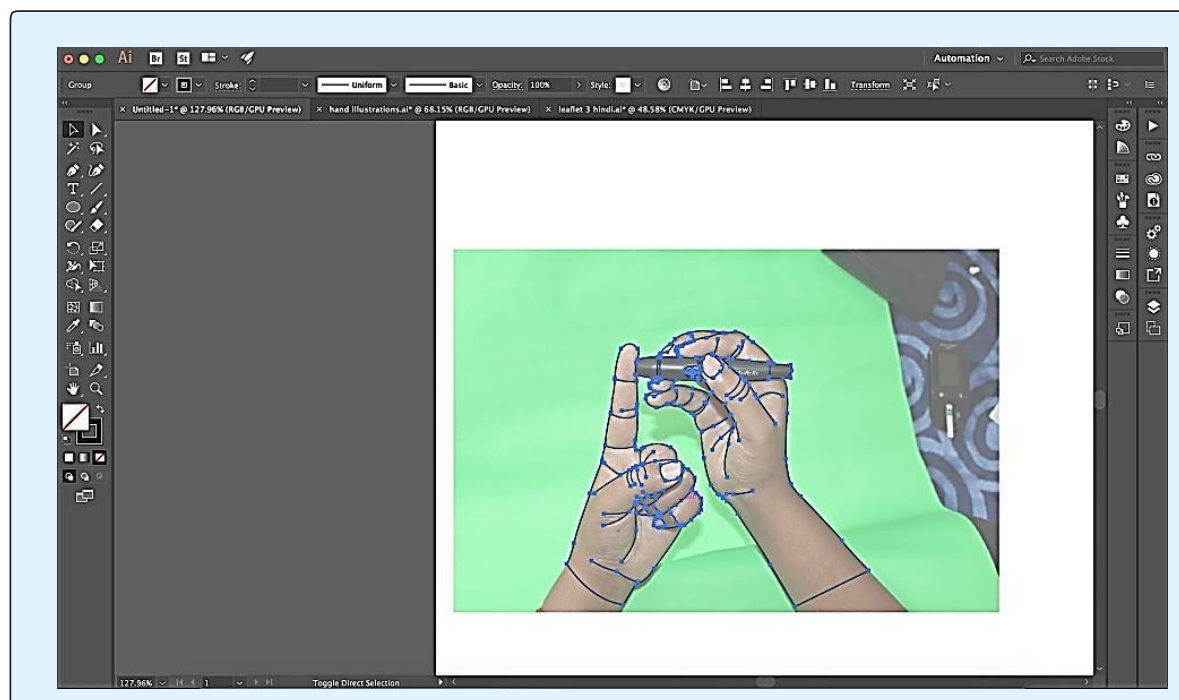

Figure 11: Hand Illustrations.

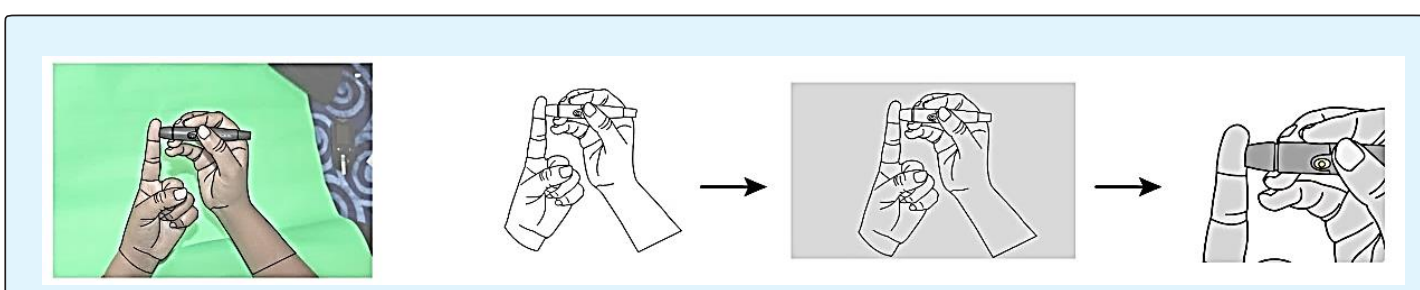

Figure 12: Making of hand illustrations.

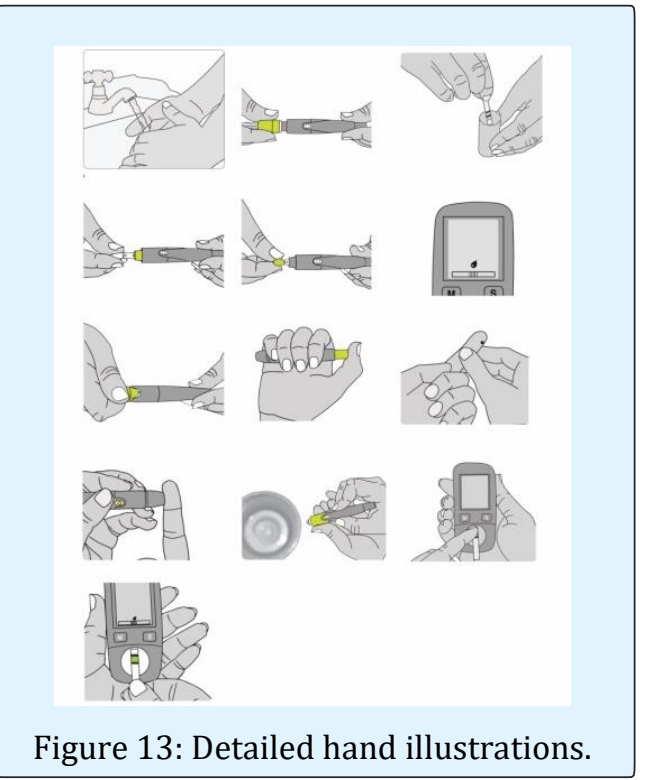

Chatterjee S. Enhancement of Information Design and its Retrieval in Glucose Monitoring Device. Ergonomics Int J 2019, 3(1): 000190.

\section{Icons}

The most visible and coming across icons were designed which are found out to be important while doing task or understanding the results. Icons considered for redesigning were blood dropping icon, Icon for waiting for result, icon for pre and post meal.

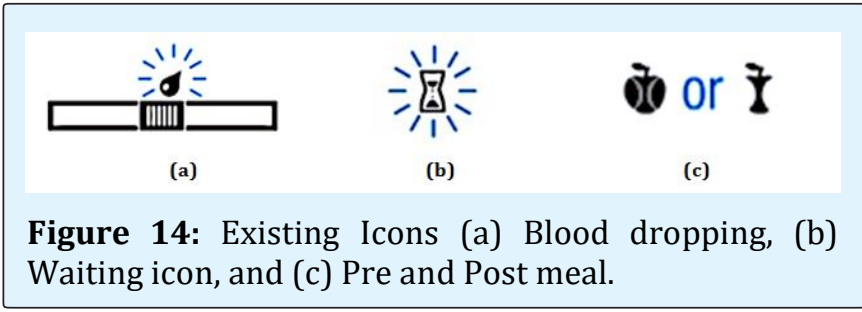

\section{Conclusion and Scope of Future Work}

Health care sector is one of the sectors growing at its peak. With the emergence of new diseases its focus is 


\section{Ergonomics International Journal}

moving towards the monitoring and precautions related with the diseases instead of only searching for best possible cure. These needs are identified by the doctors, engineers and designers and they are collaborating to find the best solutions.

The present work focuses on redesigning the leaflet as well enhancing the interface of the glucose meter. There is several kind of glucometer already available on market but the study conducted on the meter which is widely available in India (i.e. glucose meter which comes with test strips). Focusing the cognitive and interactive behavior of user with the meter new design is developed. Hence no change in the structure or embodiment of the meter is done. Several methodologies followed to gather both qualitative and quantitative data. Methodologies followed for the user research were questionnaire survey, direct interview of patients, contextual enquiry, direct observation and instructional analysis. Online survey was conducted to withdraw the critical information on the awareness of glucose-meter and diabetes in Indian society and direct interviews were conducted at PDPM Health Center, Jabalpur, and MP as well as in Pune, Maharashtra.

While redesigning the leaflet human cognitive needs and mental model was considered. Further, the work focuses on to make the task as a simple learning process while using meter. Visual and cognitive attributes of it was also taken into consideration.

The most important phase of concept generation is taken into consideration by various sketches and evaluation methods. The designs were revised multiple times before coming on to the final concept which was best amongst all of them. The final concept chosen for leaflet was based on its reading pattern, proper legibility and conveying the task properly with simple hand illustrations, designed with double visual acuity. While designing the interface shadow of device on its screen was taken into care, message on the screen were defined in simpler way, important information was kept on the top and least on bottom. When icons were redesigned the problem of confusion was try to solve with more meaningful approach and with no supporting text. Small and simple booklet was designed for those elderly who don't want to deal with technical device or who trust more on their written records. User testing was conducted amongst the users to get their valuable feedback and suggestions which were included later in the design.
I would like to mention my learning progress throughout the study, I explored in the field of visual ergonomics in designing leaflet and packaging. I have also learnt the behavioral and cognitive aspects in case of elderly users. I have learned about conducting user research and preparing questionnaire to conduct the interviews and surveys. I have also learnt about the principles of visual ergonomics and tried to apply some of them in my designs. Studying about the colors combinations for elderly and colorblind or visually impaired individuals was also a key thing for my project. Interaction with users and doctors was also one of the thing I learn during my project. While designing interface, I have come across with its exact coding part which is usually based on hardware system in simple glucose monitoring device which lead me to make very minute changes on interface in relation to coding hardware.

Further huge scope of work is identified in this field in India, in terms of guideline formation for patient leaflet, development of readability test, designing form and aesthetics of device, designing low cost meters and designing for blinds.

\section{References}

1. https://www.cdc.gov/media/presskits/aahd/diabete s.pdf

2. http://www.madehow.com/Volume-7/GlucometerTest-Kit.html\#ixzz5CH1C1nHm

3. https://www.webmd.com/diabetes/understandingdiabetes-basics\#1

4. https://www.diabetesaustralia.com.au/type-2diabetes

5. http://www.diabetes.co.uk/what-is-diabetes.html

6. https://www.mayoclinic.org/diseasesconditions/diabetes/symptoms-causes/syc20371444

7. https://www.webmd.com/diabetes/guidelines-forbuying-and-using-diabetes-supplies\#1/

8. https://justdoc.com/blog/best-glucometer-in-india/

9. http://www.madehow.com/Volume-7/GlucometerTest Kit.html\#ixzz5CH1cz87I

10. Write it right, FDA's Good Guidance Practices, GGP's

11. http://www.colourblindawareness.org/colourblindness/ 
12. http:// gulfnews.com/leisure/health/no-diabetesand-colour-blindness-link-1.1209985/

13. https://docs.microsoft.com/en-us/typography/fontlist/verdana

14. http://typedia.com/explore/typeface/verdana/

15. https://www.webdesignerdepot.com/2010/01/thesimplicity-of-helvetica/

\section{Papers}

16. Mathur KN (2005) Diabetes mellitus its diagnosis and treatment.
17. Anne C, Wendy AR, Arthur D (2002) Effectiveness of audio and visual training presentation modes for glucometer calibration. Proceedings of the Human Factors aand Ergonomics Society 46th Annual Meeting-2002, pp: 2059-2063.

18. Wendy AR, Mykityshyn AI, Campbell RH, Fisk AD (2001) Analysis of a "Simple" Medical Device. Ergonomics in Design: The Quarterly of Human Factors Applications, pp: 6-14. 